\title{
THE ATTEMPT TO USE LEVELLING RODS FOR TESTING METRIC PROPERTIES OF SURVEYING INSTRUMENTS, WHICH ARE USED FOR REFLECTORLESS DISTANCE MEASUREMENTS
}

\author{
Ewa Świerczyńska, Maria Kołakowska \\ Warsaw University of Technology \\ Faculty of Geodesy and Cartography, Warsaw, Poland
}

\begin{abstract}
This paper presents results of two experimental cycles of measurements performed with the use of the terrestrial laser scanner Z+F IMAGER 5006h and the reflectorless tacheometer Leica TPS 1202. These tests aimed at determination of metric properties of surveying instruments, which are used for reflectorless distance measurements and which are often applied to project the geometry of objects. In the course of research works issues influencing the reflection of a laser beam by the measured surface, as well as their influence on the data quality. In order to analyse metric properties of applied instruments, levelling rods were used as test fields of geometrically specified division. It was stated basing on the performed analyses, that the influence of the incidental angle of a laser beam on the accuracy of reflectorless measurements is included within the limits of the error of distance measurements of a given instrument. However, the uniform trend of increasing differences between measured values and the nominal value may be noticed, together with the increase of the incidental angle of the axis of collimation on the measured surface of the test field.
\end{abstract}

Keywords: terrestrial laser scanning, reflectorless measurements, accuracy of measurements

\section{Introduction}

\subsection{The idea of reflectorless distance measurements}

Dynamic development of surveying instruments, and, in particular, introduction of video-tacheometers and terrestrial laser scanners resulted in situation when reflectorless distance measurements are mostly applied in surveying operations. 
They allow for performing distance measurements for arbitrary surfaces, without placing reflective foils or prisms. It is particularly important for monitoring of changes which occur within engineering structures as a result of external factors, or for inventorying geometrically complex structures, where are difficulties in selection or signalling the appropriate number of control points. Remote measuring systems, based on reflectorless distance meters, which have become popular recently, are the solution of described situations (Woźniak, 2009).

The distance measurement with or without use of a prism, is performed electronically. It is based on propagation of electromagnetic waves with a specified velocity in the space (Wanic, 2007). At present, it is the most popular method of determination of distances. This technology comprises, first of all, precise registering of time, which is required for the electromagnetic signal to pass the distance between the surveying instrument to a given point and back. Radiation is emitted by the emitter of the electronic distance meter and then the signal is reflected by a prism located at the measured point or, directly by the tested surface. The returning beam is detected by the receiver of the distance meter. In impulse distance meter the distance between the surveying instrument and the given point is determined as a linear function of the registered time of passing the electromagnetic wave, which carries the measuring signal and its velocity in the specified environment. But in phase distance meter the distance is determined as a function of electromagnetic wave velocity in the specified environment, the phase difference between emitted and returning wave and its frequency.

The general idea of electronic distance measurements may be simply discussed, but it should be noticed that its practical implementation, in particular implementation of reflectorless measurements, is far more complicated. The accuracy of reflectorless measurements depends on many factors, which should be considered when a distance meter is used. As it turns out from some recent experiments, for example according to research in (Lenda, 2005), for the majority of surfaces, independently on their colours and textures, the instrument registers a smaller distance when the beam incidence angle decreaseslt was also stated that the range of measurements depends on texture of surfaces (the smoother the surface the longer the range), their colours (dark colours, as well as blue and green result in shorter distances) and on the beam incidence angle (the smaller the angle the shorter the range). Obviously the beam emitted by the distance meter is also influenced by the air temperature and humidity.

\subsection{Surveying instruments which are used for reflectorless distance measurements}

At present, all manufacturers of surveying instruments offer devices which may be used for reflectorless distance measurements. The mostly advanced constructions of distance meters allow for measuring distances exceeding $1 \mathrm{~km}$ length, without using prismatic reflectors or reflective tape. Topcon DS Series automated tacheometers allow for reflectorless measurements up to $1000 \mathrm{~m}$ length with the accuracy of $\pm(2$ $\mathrm{mm}+2 \mathrm{~mm} / \mathrm{km}$ ), and TOPCON GPT series tacheometers - even up to $2000 \mathrm{~m}$ with the accuracy of $\pm(10 \mathrm{~mm}+10 \mathrm{~mm} / \mathrm{km}$ ) (Topcon, 2013). However, it should be noticed that the longest range of laser distance meters relates to measurements performed in the optimum conditions. Usually, such long distances may be measured, pointing in the darkness or in illumination, to the white, dry and smooth target (Strach, 2007). However, the size of the distance meter spot is not without 
significance for such large distances. Various sizes of the distance meter spot are available in geodetic market (for example: Leica Scan Station spot size at $10 \mathrm{~m}$ is 4 $\mathrm{mm}, \mathrm{Z}+\mathrm{F}$ IMAGER $5006 \mathrm{~h}$ spot size at $10 \mathrm{~m}$ is $3,2 \mathrm{~mm}$ ), the smaller the spot the more accurate measurement (Kersten, 2009).

Instruments, which are used for reflectorless distance measurements, which are mostly applied in surveying practice, are electronic tacheometers, videotacheometers and terrestrial laser scanners. The advantage of tacheometric technology is the repeatability of observations and the possibility to register lines of the object discontinuity. Unfortunately, in the case of great number of details this method becomes time consuming. Thus allowing for measurements of the limited number of details. On the other hand, terrestrial laser scanning, due to its high precision and speed of data acquisition is one of the most effective methods of measurements today. Geometry, dimensions and technical conditions of objects may be determined with use of the acquired point cloud within a relatively short time.

This technology is applied during engineering measurements concerning investigation of technical conditions of constructions, as well as other concrete and steel structures. Terrestrial laser scanning is also a popular method used frequently for deformation measurement (Monserrat et al., 2008), in the process of documenting historical buildings and cultural heritage (Bahadir et al., 2010) or automatic measurements of tree stems (Lindberg et al., 2012) etc.

\subsection{Testing surveying instruments used for reflectorless distance measurements}

Each measuring instrument is characterised by two accuracies: nominal accuracy specified by the manufacturer, and practical accuracy, which depends on many factors. General methods and procedures of testing are included in ISO standards approved by the International Normalisation Committee. The ISO 17123 set of standards, Optics and optical instruments - Field procedures of testing surveying and field instruments, consisting of seven parts concerns the majority of instruments, which are applied in the surveyors' practice, such as: levels, theodolites, electrooptical distance meters, electronic tacheometers, levels with rotating lasers, optical plummets (PN-ISO, 2005).

Standards concerning the surveying instrument science describe procedures of testing instruments in field conditions, which aim at detection of the, so-called, practical accuracy of a given surveying instrument before it is used to perform particular surveying tasks. The advantage of practical application of such methods is the possibility to evaluate the practical accuracy of instruments according to the uniform rules (Pawłowski, 2008). Besides, they permit to implement the author's plan of observations, assuming the appropriate level of knowledge of mathematical statistics (Strach, 2007). The disadvantage of such standard works is the lack of appropriate testing procedures for some, recently developed instruments, applied in surveying. Among the instruments, which are used for reflectorless distance measurements, testing procedures were developed for electrooptical distance meters and electronic tacheometers; however standards, which would regulate issues related to calibration of terrestrial laser scanners have not been developed yet. In contrast to other existing terrestrial surveying instruments, there are not many benchmark tests available for Terrestrial Laser Scanner (TLS) data quality specifications (In Su Lee et al., 2010; Zámečníková, 2004). Many attempts aiming at development of universal procedures of calibration of scanners, have been 
undertaken by the Polish and foreign research centres (Wunderlich et al., 2013). However, any of the recently developed methods has not been approved as the official standard of testing such instruments. Due to the above, there is still a need to perform research and experimental works concerning metrical features of instruments used for reflectorless distance measurements.

\section{Methodology of research}

\subsection{Objectives of research works}

The basic objective of analyses presented in the paper is to investigate selected aspects of acquisition and processing of data acquired by the terrestrial laser scanner Z+F IMAGER 5006h and the reflectorless tacheometer Leica TPS 1202. Parameters of this instruments: Z+F IMAGER 5006h - resolution range $0.1 \mathrm{~mm}$, resolution vertical $0.0018^{\circ}$, resolution horizontal $0.0018^{\circ}$, beam diameter $3 \mathrm{~mm}$ circular ( $1 \mathrm{~m}$ distance ); Leica TPS 1202 - vertical and horizontal accuracy 2", accuracy of distance measurements without reflector - $\pm(2 \mathrm{~mm}+2 \mathrm{ppm})$, laser spot size at $30 \mathrm{~m} 7 \mathrm{~mm} \times 10 \mathrm{~mm}$

Analyses were performed with respect to projection of geometry and properties of objects. The issues concerning factors, which influence on the accuracy of obtained results, are also discussed.

Levelling rods (Fig.1) were used for determination of metric properties of the terrestrial laser scanner; they played the role of a test field. The possibility to utilise the scale placed on the levelling rod, as a pattern of known distances. The process of multiple scanning the levelling rods under various angles and from various distances resulted in point clouds, which projected the test field of specified geometric properties. The analysis of metric properties of instruments used for reflectorless distance measurements was performed basing on the surveys of intervals between the selected lines of the levelling rod division, registered by the reflectorless tacheometer and the terrestrial laser scanner.

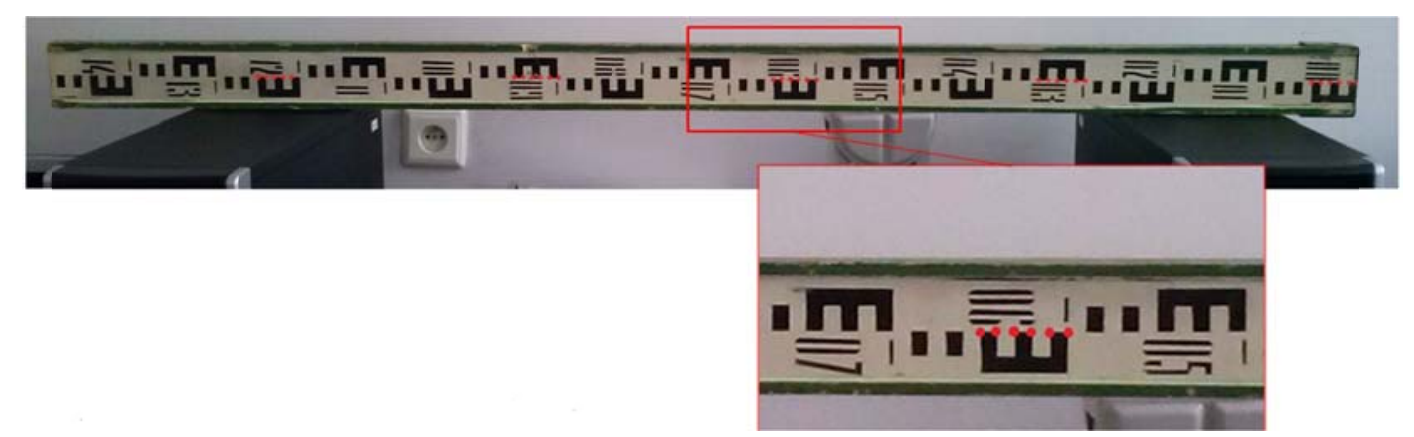

Fig. 1. Levelling rods playing the role of a test field

\subsection{Implementation of field works}

Performed tests were based, first of all, on implementation of experimental surveys of test fields of specified geometric features. Such solution allowed for controlling the size of projected test field and for determination of the accuracy systematics of observations, performed by the terrestrial laser scanner and the tacheometer (Fig. 2). 


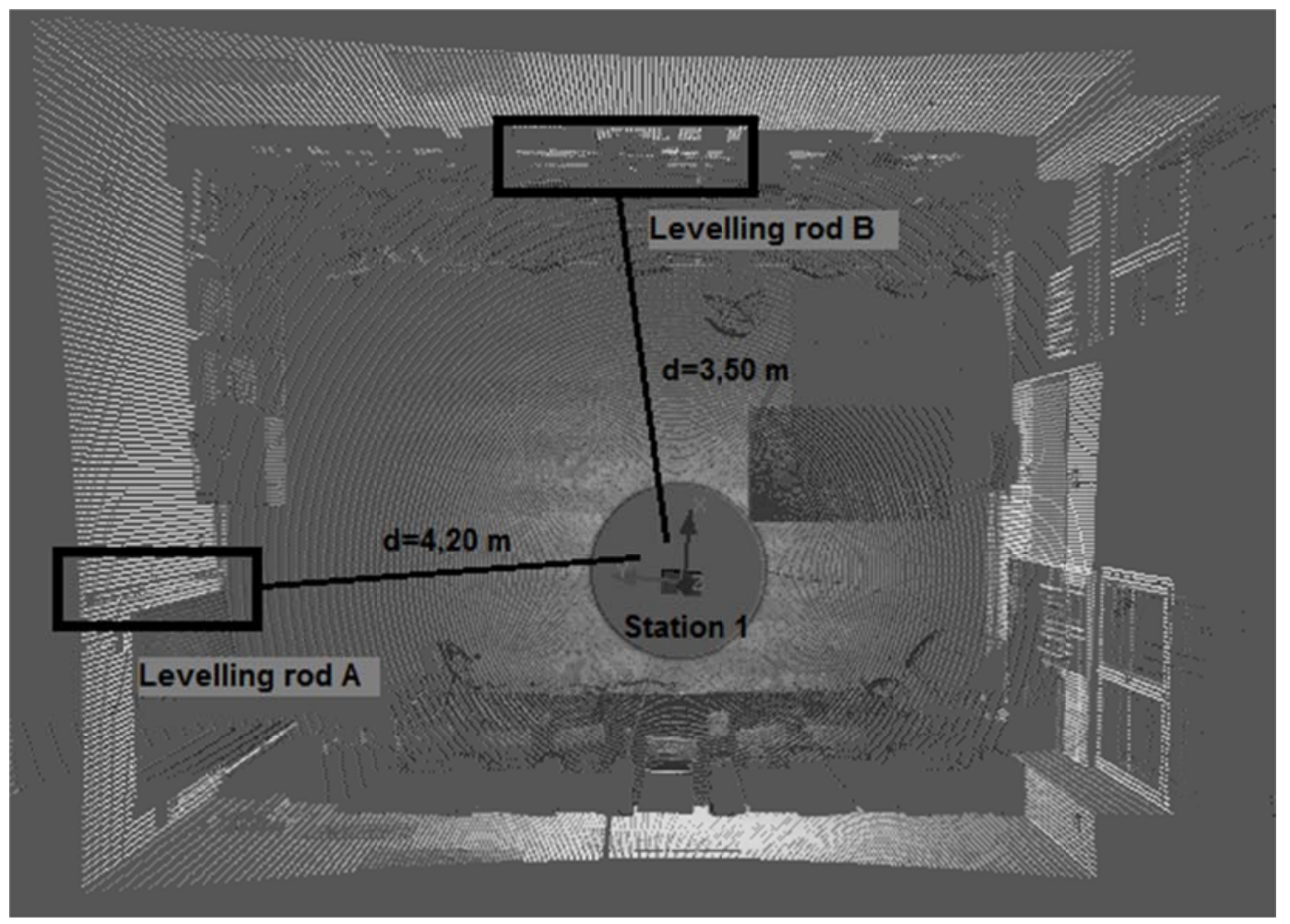

Fig. 2. Position of the station with respect to levelling rods during the 1st cycle of test measurements - a view from the top

Field works comprised two independent cycles of test measurements. All observations were registered at the same room, i.e. in similar atmospheric conditions: the room temperature, moderate humidity, no wind or excessive solar radiation. The first cycle of measurements was performed from one station, which location is presented in Fig. 2. After scanning the surface of the levelling rods from a measuring station, the same tribrach was used to position the tacheometer in order to perform the reflectorless measurements of selected points of the levelling rod division. The height of center point above the tribrach was not the same for both instruments (height difference was about $9 \mathrm{~cm}$ ), but location of center points of both instruments was the same in the $X Y$ plane. In this way incidence angles of the laser beam on surface of the levelling rods were approximately the same during measurements by using both instruments.

This procedure allowed for ensuring that during the surveys performed with the use of both technologies, the incidence angle of the laser beam on the measured surface in the horizontal plane was similar to the incidence angle in the vertical plane. This was particularly important due to positioning two levelling rods in orthogonal directions. The rod A was vertically positioned along the wall in the room where the experiment took place. The rod B was positioned horizontally.

The second cycles of measurements included measurements of two levelling rods from two stations, which positions are presented in Fig. 3. The same methodology of measurements was applied. However, the second station was added and the rod B was positioned horizontally, with the black-and-white scale patterns directed upward. Thus, successive points of the rod were registered from the station 1 under various reflection angle in the vertical plane and, therefore, in the horizontal plane, and they were reversely registered from the station 2 . 


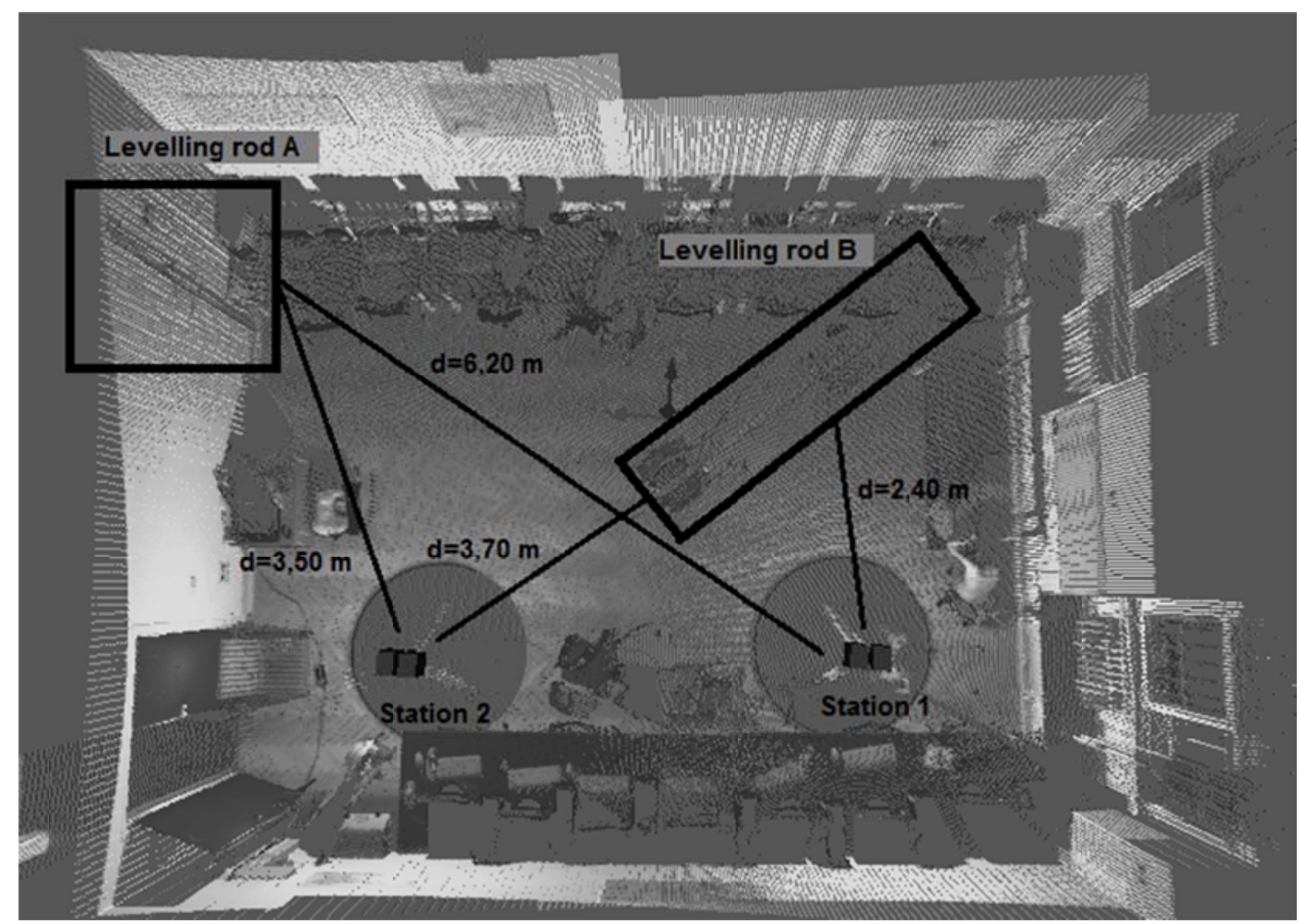

Fig. 3. Position of the stations with respect to levelling rod during the 2 nd cycle of test measurements - a view from the top

During both cycles of measurements test fields were scanned with the average cloud density of 250,000 points $/ \mathrm{m}^{2}$, what results in $2,0 \mathrm{~mm}$ distance between points (the levelling rods scanned from the highest distance have $3,0 \mathrm{~mm}$ distance between points). Tacheometric measurements required manual discretisation of the levelling rod surfaces; that is why measurements of selected points of the central part of the scale in two positions of the instrument vertical circle were performed. It is worth to mention that only borderlines between black-and-white parts of the test field were registered.

\subsection{Methodology of elaboration of results}

Obtained data was analysed and compared. The basic objective of these operations was to test the influence of the reflection angle of the laser beam from the measured surface on the accuracy of projection of geometric features of the scale of levelling rods.

The incidence angle of the laser beam has been defined here as the angle between the sight line of the instrument and the normal line to the given surface. In the case of the horizontally positioned levelling rod the influence of the horizontal angle of incidence was analysed; in the case of the vertically positioned rod - the vertical angle of incidence was analysed (Fig. 4). 


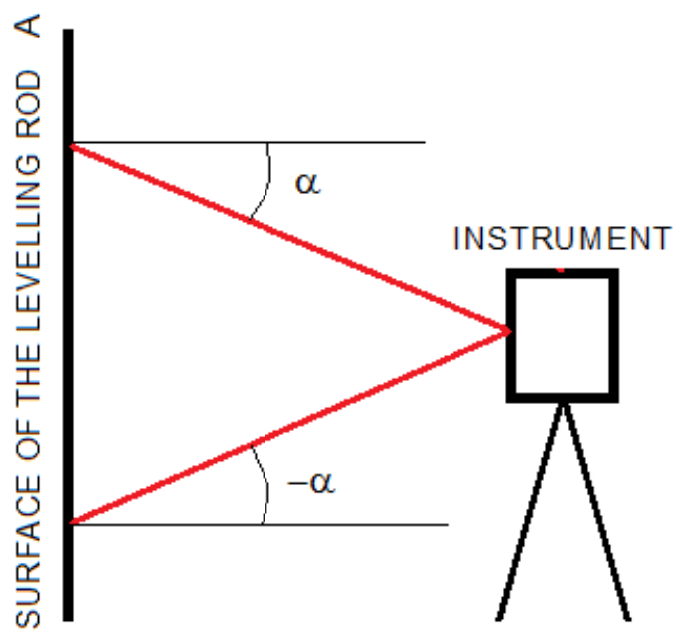

(a)

\section{SURFACE OF THE LEVELLING ROD B}

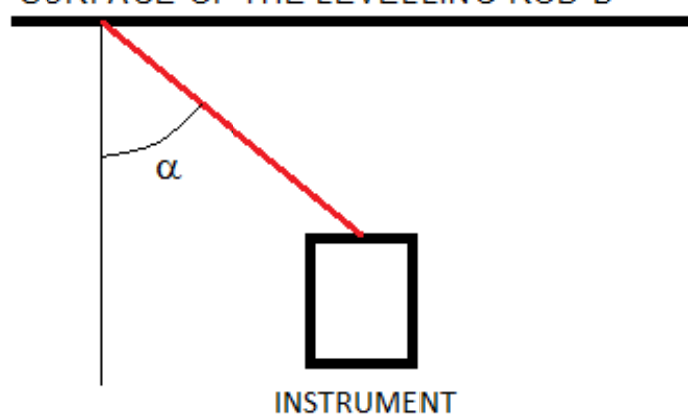

(b)

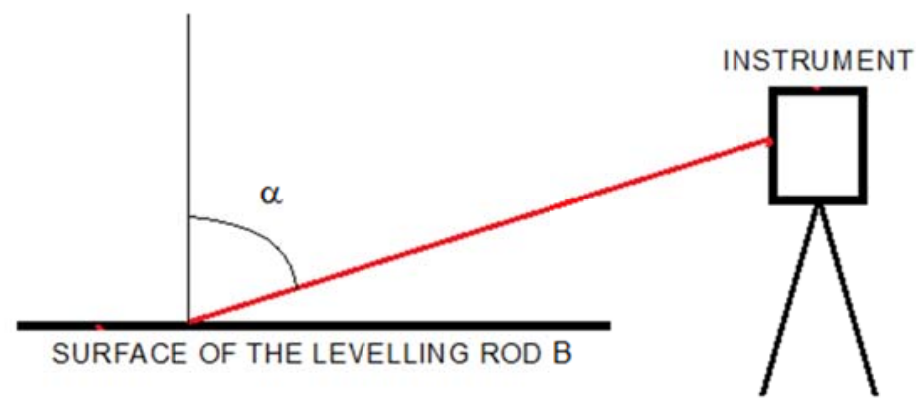

(c)

Fig. 4. The incidence angle of the laser beam on the measured surface: (a) - of the rod $A$ measured in the vertical plane (during the 1st and 2 nd cycle of test measurements), (b) - of the rod B - in the horizontal plane (during the 1st cycle of test measurements), (c) - of the rod $\mathrm{B}$ - in the horizontal plane (during the 2 nd cycle of test measurements)

The pattern on the levelling rod was measured separately for tacheometric data and laser scanning data. Basing on the co-ordinates of points observed by means of the tacheometer, distances between lines of the levelling rod were calculated. Measures of the pattern in particular point clouds were determined in two ways:

- by measurements of the distances between lines of the rod, directly on the scan, by means of Ascan software (repeatability of the method was $0.5 \mathrm{~mm}$ ),

- by calculation of distances between lines of the rod basing on coordinates measured on the scan using Z+F Image Control (repeatability of the method was $0,8 \mathrm{~mm}$ - it was calculated on the basis of 10 measurements of the same point).

Results of all calculations (using three methods: generation of techeometer observations, generation of scan obserwations by means of Ascan software and generation of scan obserwations by means of $Z+F$ Image Control) were presented on diagrams, which illustrate the influence of the angle of incidence of the laser beam on the difference between the measured size of the pattern and its nominal size. Additionally, standard deviations were calculated for data projecting particular parts of the test field. 


\section{Discussion of results of tests}

\subsection{Analysis of results of the 1 st cycle of measurements}

Basing on the data from the 1st test measurements the diagram, which presents results of measurements of individual black lines for particular length of the levelling rod was developed (for the length interval of 0-5 cm, 30-35 cm, 60-65 cm, 90-95 cm and $120-125 \mathrm{~cm}$ ); the levelling rod was horizontally positioned. Comparing deviations of registered values from the nominal pattern value (which was asumed to be $1 \mathrm{~cm}$ ), considerable discrepancy between the value of this deviation and the incidence angle of the laser beam. On the other hand, basing on graphical presentation of results of data elaboration, which projected the horizontally positioned levelling rod, the better metric characteristics of tacheometric measurements was observed. Deviations calculated from coordinates of particular spot heights did not exceed $0.5 \mathrm{~mm}$, while differences between the nominal value and the value measured on the point cloud with the use of the Ascan software were smaller than $1 \mathrm{~mm}$, and in the $Z+F$ Image Control software they were even greater than $1 \mathrm{~mm}$ (Fig. 5).

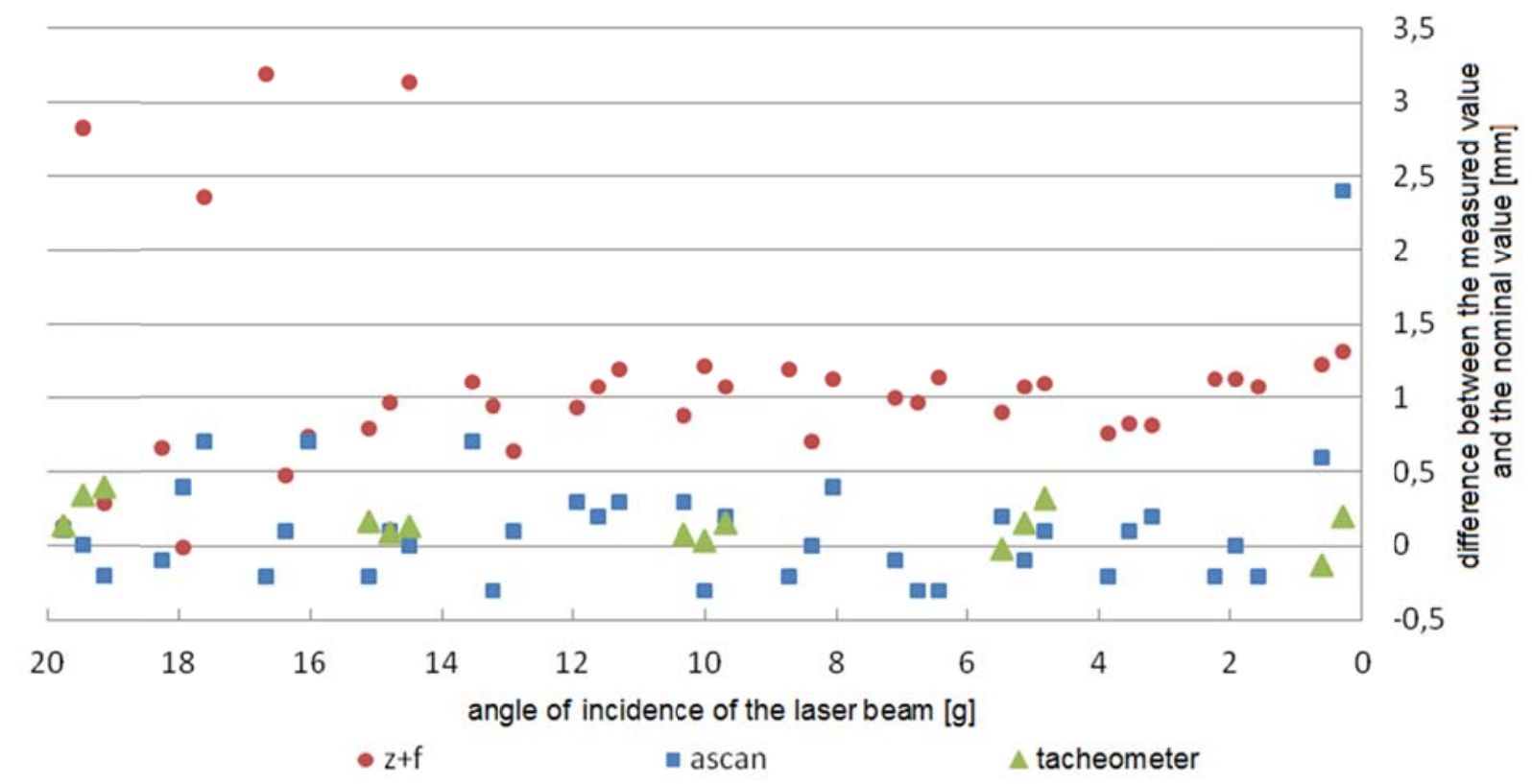

Fig. 5. Results of measurements of the pattern on the horizontally positioned levelling rod

Different results were obtained after graphical elaboration of results of measurements of the pattern on the levelling rod, which was vertically positioned. Much better metric features, i.e. the smaller value of the standard deviation presented on the horizontal axis of the diagram, characterised the data obtained from the point cloud using the Ascan software. A little bit worse results were obtained from tacheometric data processing and the worst results were obtained after measuring the pattern on the point cloud using the Z+F Image Control software. Similarly to the first case the direct relation between the deviation from the nominal value and the incidence angle of the laser beam was not observed (Fig. 6). 


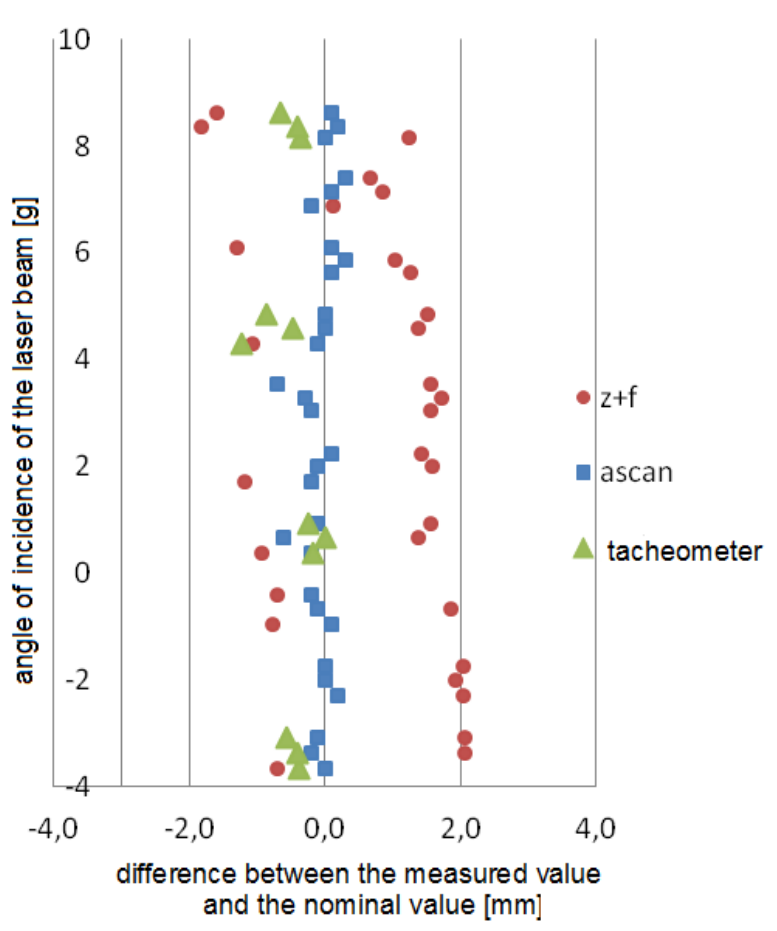

(a)

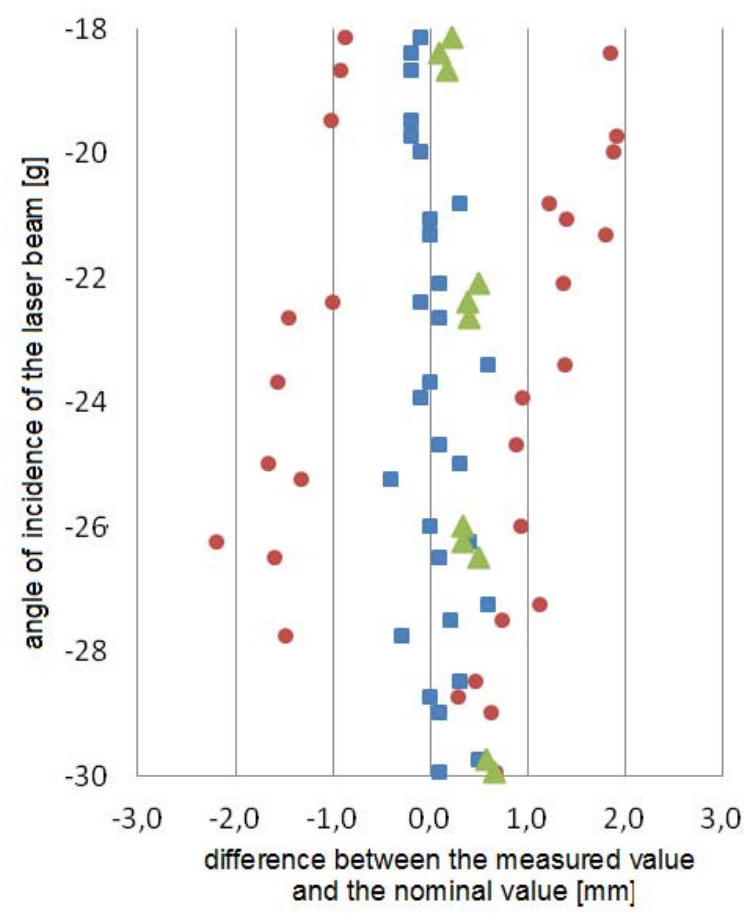

(b)

Fig. 6. Results of measurements of the pattern on the vertically positioned levelling rod: (a) - the upper part of the rod, between 2 and $3 \mathrm{~m}$; (b) - the bottom part of the rod between 0 and $1 \mathrm{~m}$

The levelling rod, which was vertically positioned (using the spherical level, which accuracy was 8') during the measurements, was additionally analysed. Its horizontal deflection towards the measuring station was visualised. As it turns out from graphical data processing, the horizontal deflection of levelling rod from the plumbline depends on the incidence angle of the laser beam. This was particularly well visible in the bottom part of the test field, where the incidence angle of the sight line reached 30 grad. Besides, basing on the diagram (Fig. 7) which presents the relation between the horizontal deflection of the levelling rod with respect to the plumb line, from the incidence angle of the laser beam, the specific construction feature of the electronic tacheometer was noticed. The same phenomenon was observed for each of the levels of the levelling rod, for which one-centimetre lines of the rod division were discretely registered. Horizontal distances to spot heights located between the white (at the bottom) and the black (at the top) lines were shorter than distances to spot heights located between the lines reversely oriented. On the intersection of the levelling rod it is visible as characteristic "zigzags" of the same shape and of different size (Fig. 8a). This proves a major impact on measurement results the eccentricity between the sight line of the instrument and the sight line of the laser distance meter in the tacheometer. The instrument specification does not disclose how big this eccentricity is but it is connected with different reflectivity factors of the black and white surface (white colour is characterised by the higher ability to reflect the laser beam). 


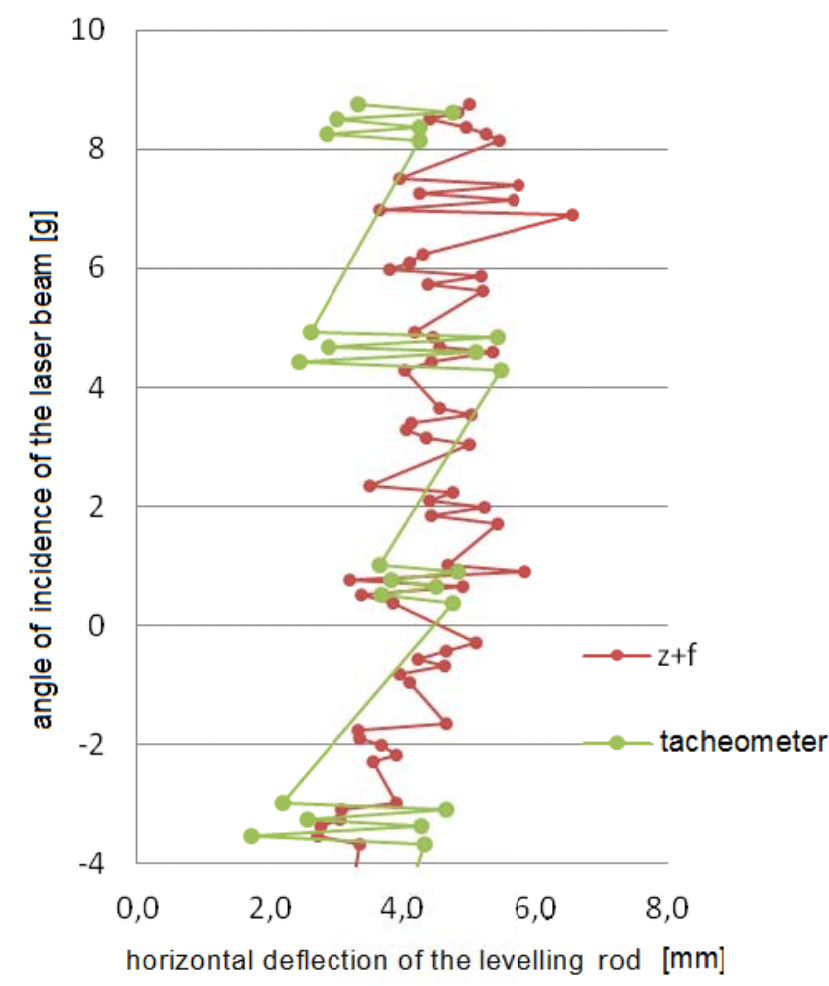

(a)

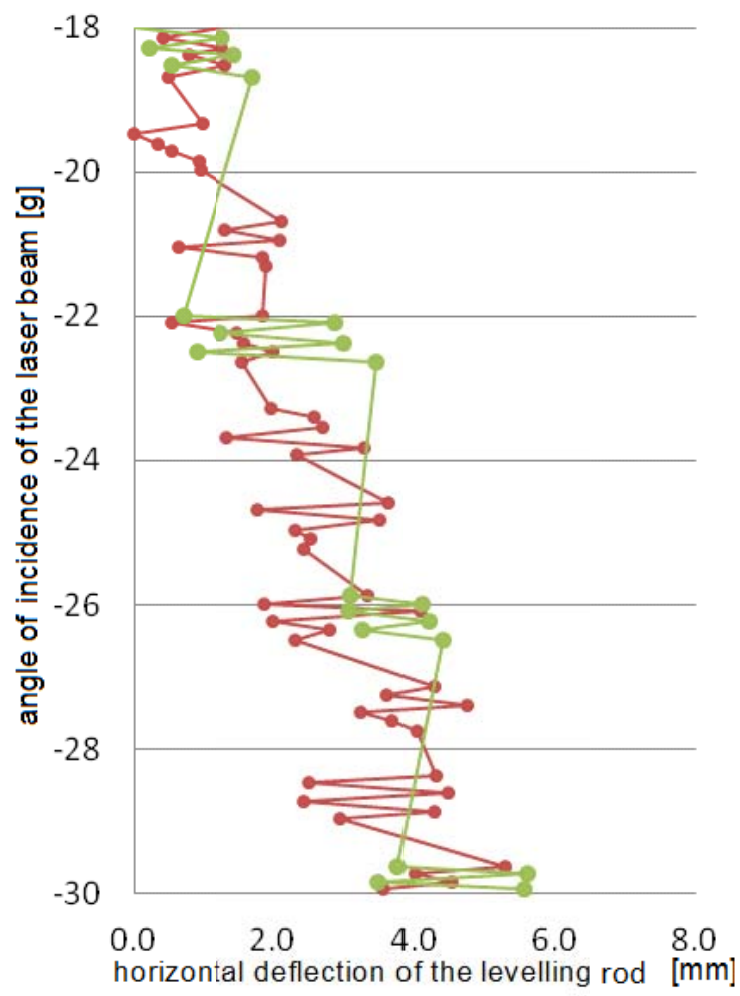

(b)

Fig. 7. Intersection of the vertically positioned levelling rod (horizontal deflection of levelling rod from the plumb-line: (a) - the upper part of the rod, between 2 and $3 \mathrm{~m}$;

(b) - the bottom part of the rod between 0 and $1 \mathrm{~m}$

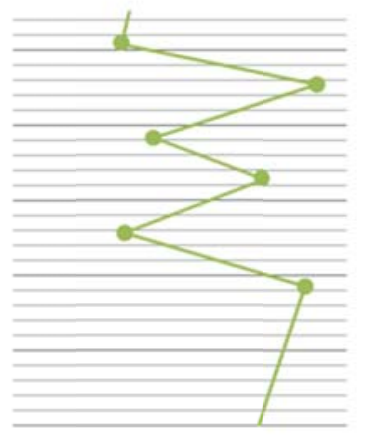

(a)

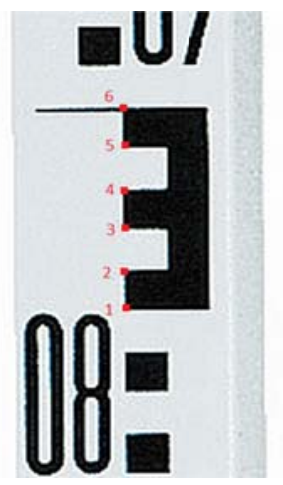

)

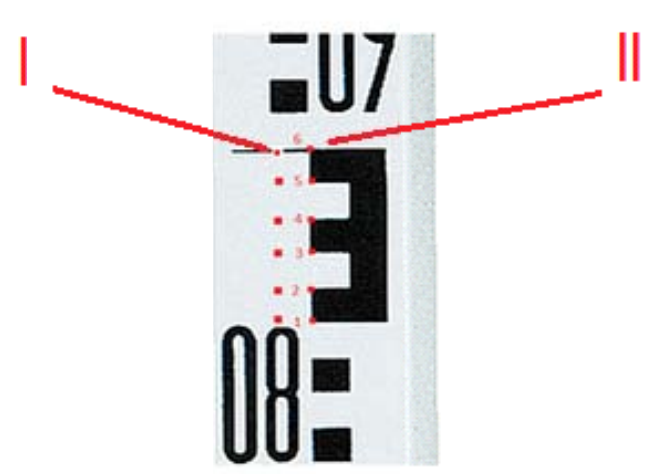

(b)

Fig. 8. (a) The sight line of the instrument does not overlap with the axis of the laser distance meter in the tacheometer. Horizontal distances to spot heights located between the white (at the bottom) and the black (at the top) lines are shorter than distances to spot heights located between the lines reversely oriented. (b) Two-stage measurement of an individual spot height: I - measurement of the vertical and horizontal angles,

$$
\text { II - measurement of the distance on the white field }
$$


One of ways which allow to avoid the situation presented in Fig. 8 and its influence on the reflectorless distance measurements is the two-stage measurement of an individual spot height on the pattern, being the levelling rod. In such experiments this should rely on pointing to the selected point, registering the vertical and horizontal directions and, on the minimum shift of the sight line to the area of the white field of the levelling rod and measurement of the distance. Unfortunately, this method cannot be practically used and, therefore, it should be considered as an argument, which confirms the comments concerning colours of targets and not as the method of observations.

\subsection{Analysis of results of the 2 nd cycle of measurements}

The second cycle of measurements was performed after analysing data acquired within the first cycle.

In order to check the correctness of application of the two-stage measurements of individual spot heights, the second cycle was started from testing the repeatability of tacheometric observations. Deviations from the pattern were presented graphically, in relation to the incidence angle of the laser beam for points measured at the stations 1 and 2 . The sight line of the tacheometer, positioned at the station 1, was reaching the surface of the vertical levelling rod under the smaller horizontal angle. The sight line of the tacheometer positioned at the station 2, was reaching the surface of the horizontal levelling rod under the horizontal angle, which value was close to zero. Due to the above, deviations from the nominal value were mostly dependent on the vertical incidence angle of the laser beam.

Diagrams in Fig. 9 and Fig. 10 present results of measurements of both levelling rods in both positions of the telescope, and their mean values. For chosen levels $(0 \mathrm{~cm}, 30 \mathrm{~cm}, 60 \mathrm{~cm}, 90 \mathrm{~cm}$ etc.) of the rod were made surveys in 5 intervals. Fig. 9 presents results of measurements from the station 2 of the pattern on the horizontally positioned rod and Fig. 10 presents results of measurements from the station 1 of the pattern on the vertically positioned rod. In the case of each data set it may be noticed that the deviation from the nominal value increases together with the increase of the vertical incidence angle of the laser beam. This relation is visible, in particular, in the case of the horizontal levelling rod, which points were measured under very big angles (besides 70 and 90 grad). Besides, data which projects this levelling rod in the second position of the telescope is characterised by the bigger standard deviation from data acquired in the first position of the telescope. In the case of the vertical levelling rod such difference between two types of observations has not been noticed. It was finally stated that the repeatability of tacheometric measurements does not exceed $1 \mathrm{~mm}$ an error accuracy for small angles and $2 \mathrm{~mm}$ for very big angles.

During the next stage of the second cycle tacheometric observations were compared with data, acquired by means of the laser scanner. Due to high deviations from the pattern value, it was not measured in the point cloud using the Z+F Image Control software. Data from laser scanning were processed using only the Ascan software, which allowed for interpolation between neighbouring points of the point cloud. 


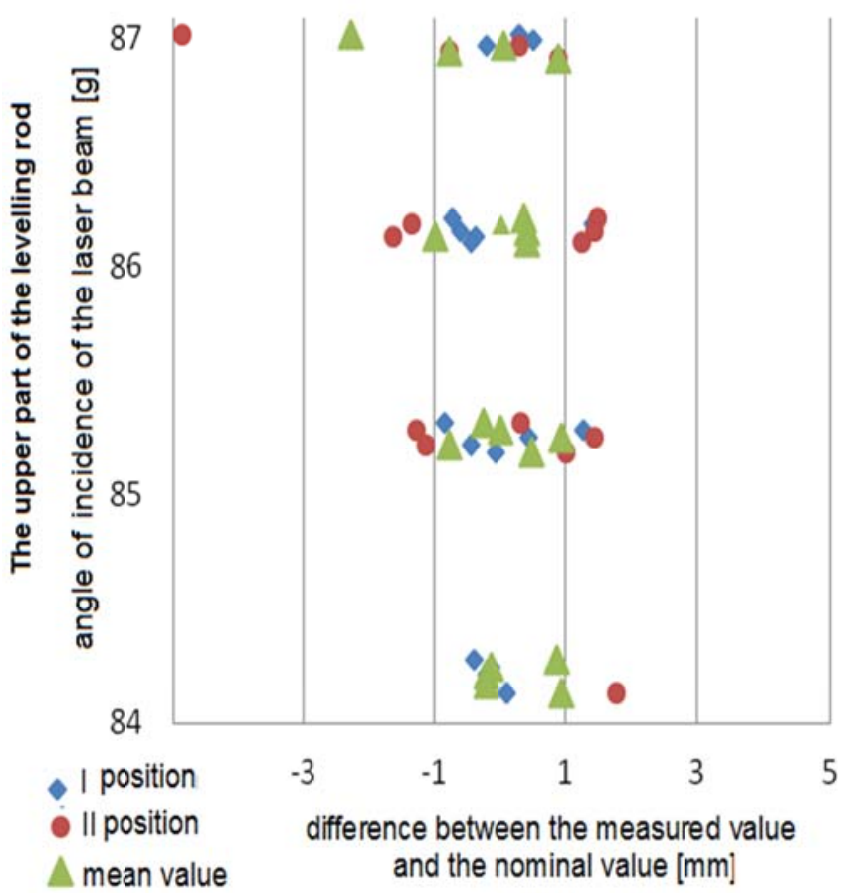

(a)

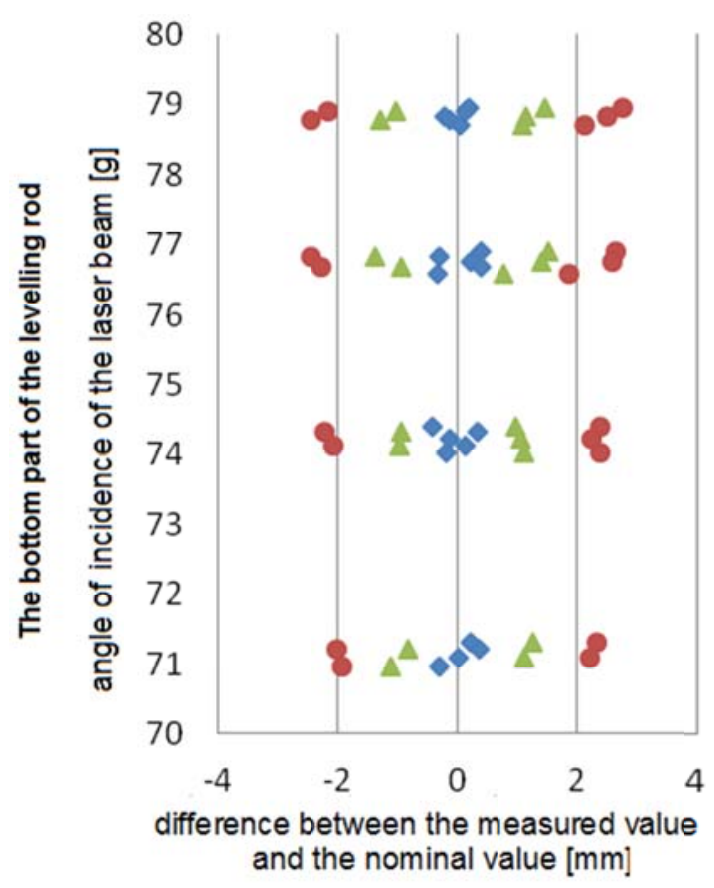

(b)

Fig. 9. Results of measurements from the station 2 of the pattern on the horizontally positioned rod: (a) - the upper part of the rod, between 2 and $3 \mathrm{~m}$; (b) - the bottom part of the rod between 0 and $1 \mathrm{~m}$

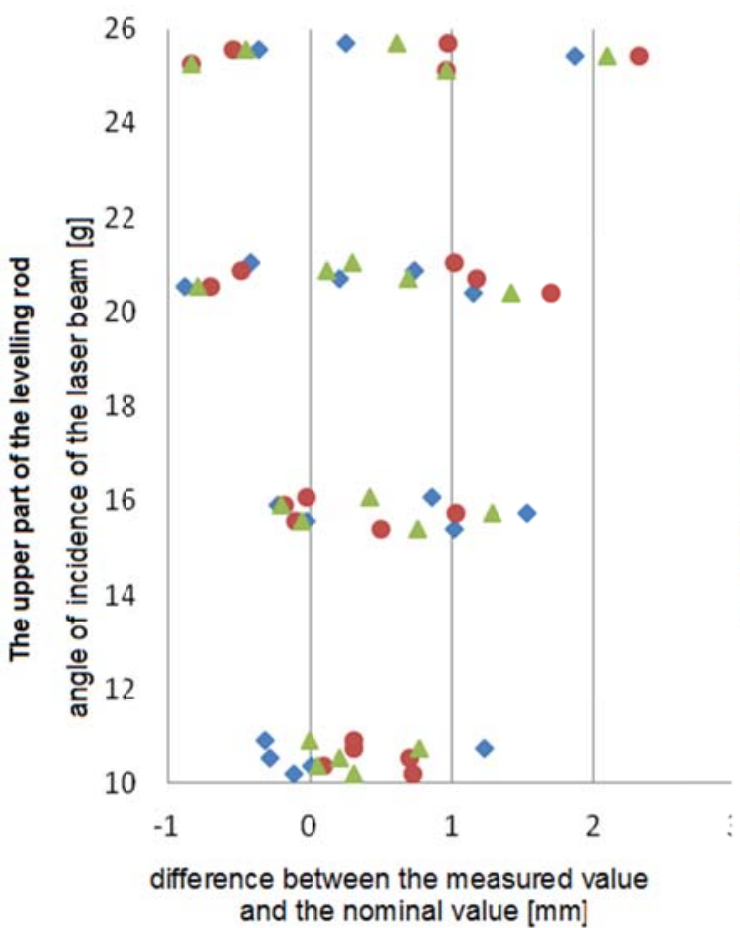

(a)

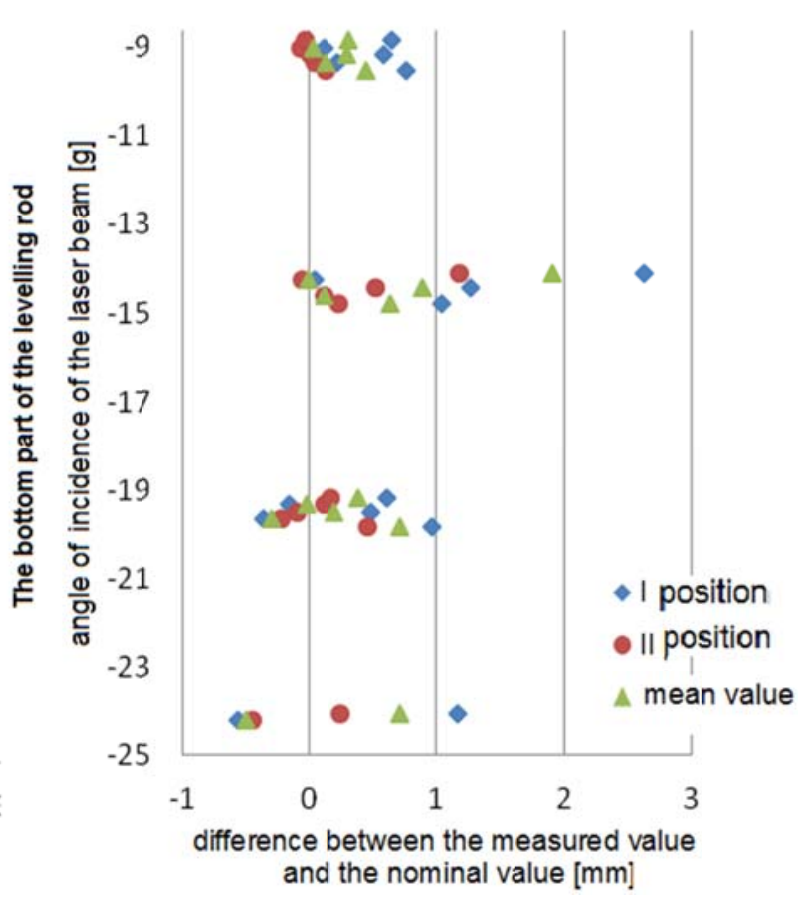

(b)

Fig. 10. Results of measurements from the station 1 of the pattern on the vertically positioned rod: (a) - the upper part of therod, between 2 and $3 \mathrm{~m}$; (b) - the bottom part of the rod between 0 and $1 \mathrm{~m}$ (the incidence angle are presented with minus for measured surface, which was located below the horizontal axis of the instrument) 
Diagrams in Fig.11 present differences between the measured value and the nominal values of the pattern for particular lengths, along the horizontal levelling rod, measured from the stations 1 and 2 . In the case of the station 1 values of the lines of division, measured in the point cloud, considerably differ from $1 \mathrm{~cm}$, while the values calculated from tacheometric coordinates better project the pattern measure. Data acquired from the station 2 is characterised by the reverse trend. Tacheometric observations have the standard deviation which is two times bigger than in the case of laser scanning data. This may be caused by the fact, that the vertical incidence angle of the laser beam on the test field surface is greater in the case of positioning the instrument at the station 2 . This data may successively prove and confirm the strong relations between the reflectorless distance measurements from the angle of incidence of the laser beam on the measured surface.

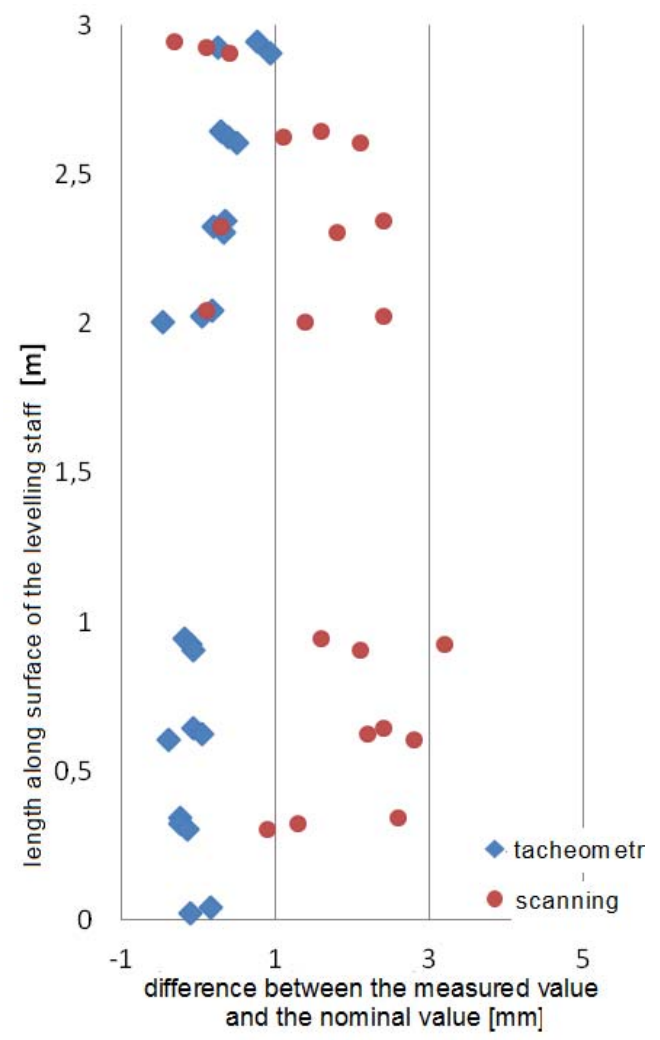

(a)

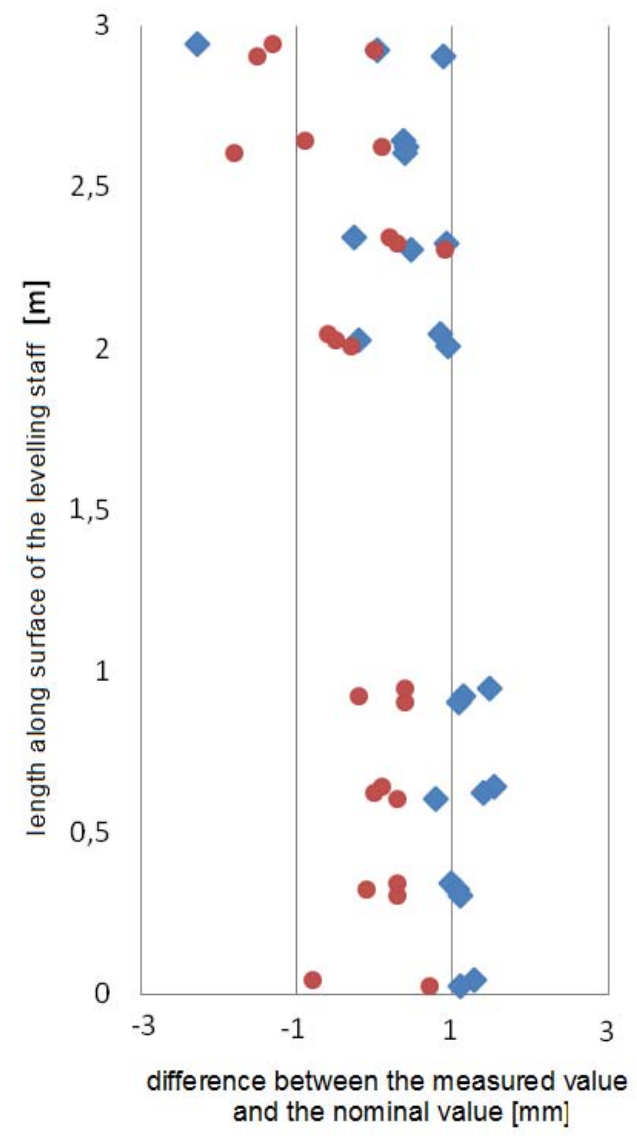

(b)

Fig. 11. Results of measurements of the pattern on the horizontally positioned levelling rod:

(a) - from the station 1; (b) - from the station 2

Next diagrams in Fig. 12 present differences between the measured values and the nominal values of the pattern for particular vertical incidence angles of the laser beam on the vertically position levelling rod, observed from the stations 1 and 2, respectively. Similarly to case of the horizontally positioned levelling rod, tacheometric data acquired at the station 1 is characterised by better metric values than the point clouds registered by the scanner, and tacheometric data acquired from the station 2 is characterised by worse metric values than laser scanning data.

It may be also caused by the bigger value of the incidence angle of the laser beam, both, the vertical and the horizontal value in this case. 


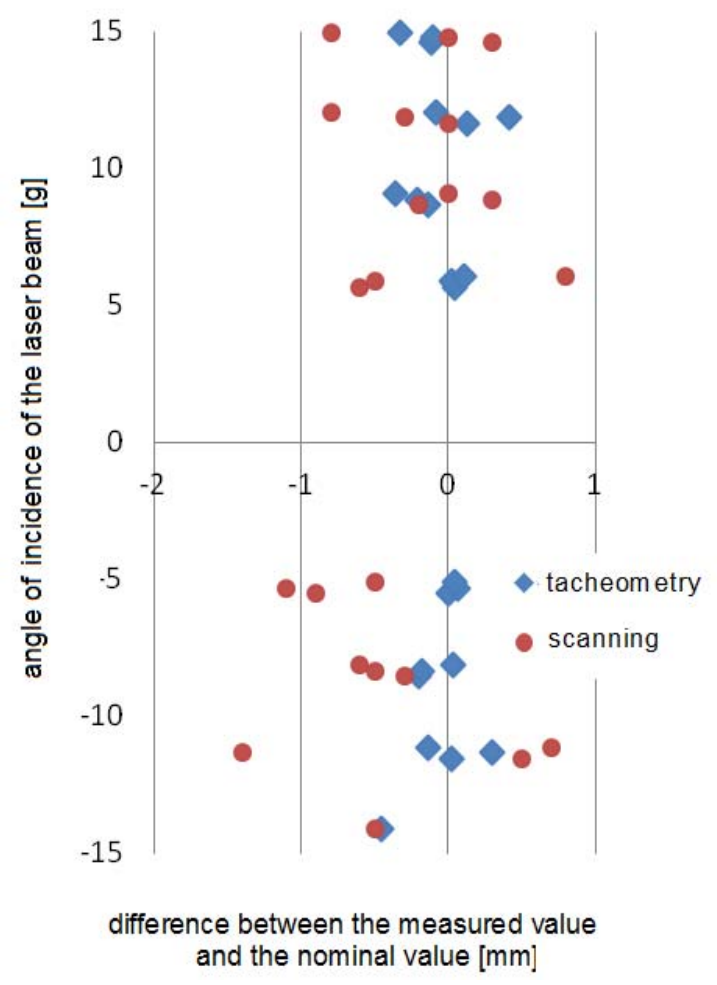

(a)

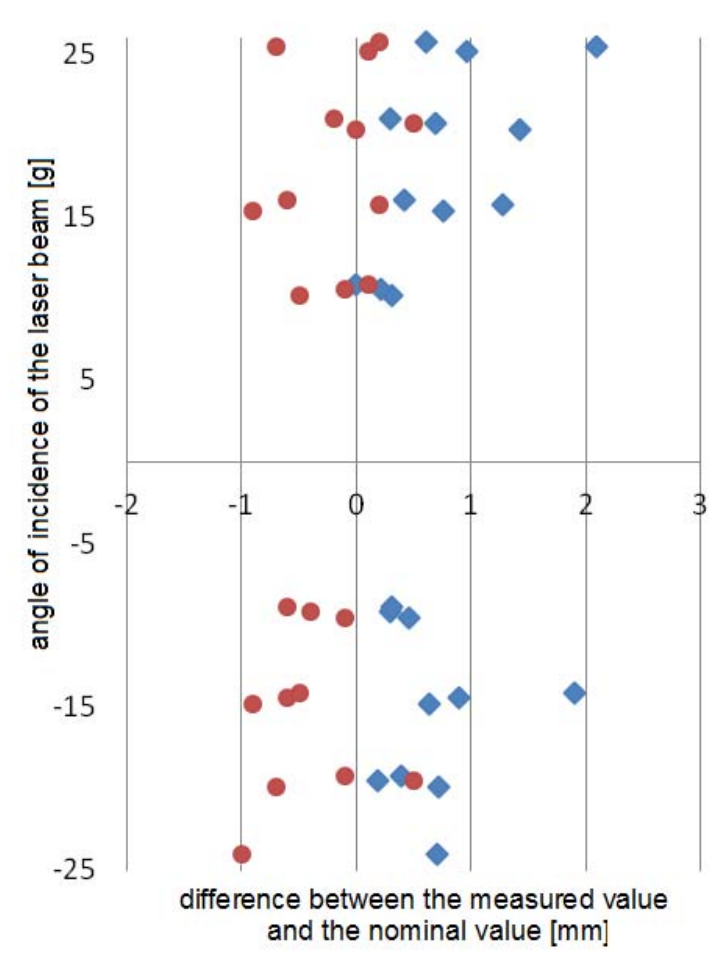

(b)

Fig. 12. Results of measurements of the pattern on the vertically positioned levelling rod: (a) - from the station 1 ; (b) - from the station 2

\subsection{Comparison of results of two cycles of measurements}

During the final stage of analyses results of two cycles of measurements were compared by means of calculation general values of standard deviations from the nominal value for each group of data. Double values presented in cells of Table 1 are the standard deviation values for data concerning the upper and the bottom part of the levelling rod. respectively. The presented list of values confirm the properties which have been stated basing on the diagrams, which were created earlier.

Tab. 1. Standard deviations for particular groups of data of the 1st and 2nd cycles of measurements

\begin{tabular}{|c|c|c|c|}
\hline & Group of data & $\sigma_{\text {tacheometry }}[\mathrm{mm}]$ & $\sigma_{\text {ascan }}[\mathrm{mm}]$ \\
\hline \multirow{3}{*}{ 1st cycle of } & Station 1 - horizontal rod & 0.20 & 0.48 \\
\cline { 2 - 4 } measurements & Station 1 - vertical rod & 0.57 & 0.22 \\
& & 0.41 & 0.25 \\
\hline \multirow{4}{*}{ 2nd cycle of } & Station 1 - horizontal rod & 0.46 & 1.40 \\
\cline { 2 - 4 } measurements & \multirow{2}{*}{ Station 2 - horizontal rod } & 0.18 & 2.07 \\
\cline { 2 - 4 } & \multirow{2}{*}{ Station 1 - vertical rod } & 0.95 & 0.90 \\
& & 0.20 & 0.40 \\
\cline { 2 - 4 } & & 0.20 & 0.48 \\
& Station 2 - vertical rod & 0.95 & 0.77 \\
\hline
\end{tabular}




\section{Conclusions}

In this paper the authors presented the first attempts to research metric properties of surveying instruments. During the implementation of research works many problems were encountered and the final results included the combined effect of many factors, such as different beam angle, power of the reflected signal, reflectance of the surface, area of the laser spot and others. In order to designate impact of individual components, the authors need to extract individual factors and analyze them independently.

Initially the authors decided to compare reference values with the values measured by the tacheometer and in the point cloud. The maximum difference between the pattern length (equal to $1 \mathrm{~cm}$ ) and the value measured in the point cloud using Ascan software exceeds $1 \mathrm{~mm}$. It probably results from data interpretation errors. This problem could be solved by the development of an algorithm which would detect the edges of the rod division, basing on the recorded intensity of reflection (between the black and white line). On the other hand, the lack of possibility to interpolate coordinates between points of the cloud in the Z+F Laser Controller results in the high standard deviation for data processed by this method, what excluded it from further considerations. For the horizontal rod tacheometric data is characterised by better metric values than the point clouds registered by the scanner, inverse situation occurs for the vertical rod.

During tacheometric measurements the authors observed that horizontal distances to spot heights located between the white (at the bottom) and the black (at the top) lines were shorter than distances to spot heights located between the lines reversely oriented. It was noticed that the biggest problems are the different power of the reflected signal (caused by the various surface colours) and eccentricity between the sight line of the instrument and the sight line of the laser distance meter in the tacheometer. Unfortunately, the instrument specification does not disclose how big this eccentricity is, but it is connected with different reflectivity factors of the black and white surface.

On the basis of diagrams and calculated standard deviations from the nominal value for each group of data in conclusions can be drawn much more problems. Basing on the performed analyses, it was stated that the influence of the incidence angle of the laser beam on the accuracy of the pattern registration, using instruments applied for reflectorless distance measurements, falls within the limits of the distance measurements error. However, from the diagrams, which present particular groups of data, the uniform trend of the increasing differences between the measured value and the nominal value may be seen, which follows the increase of the incidence angle of the sight line on the measured surface of the test field. This may be well visible for tacheometric data; however, it cannot be explicitly observed in the case of laser scanning. It follows the need to prepare some more experiments with a higher reference field to check how big is this trend and if it is also observed for laser scanning data.

The last problem was the geometry and size of the laser beam. In Leica 1202 laser beam at the distance of $30 \mathrm{~m}$ is $7 \mathrm{~mm} \times 10 \mathrm{~mm}$ in Z+F Imager 5006h laser beam is circular $-3 \mathrm{~mm}$ diameter at 1 meter. This difference may also affect obtained results of distance measurements, especially if the measured surface is not a single colour and texture.

Analysis of the results allowed us to note that the presented problem requires further significantly more complex analyzes. The results obtained at this stage 
indicate a total set of factors, the influence of which does not allow for estimation of their individual impacts. Each of presented problems should be separately considered in the future. The presented research works will be the practical introduction to successive analyses concerning the relations between reflectorless distance measurements and the angle of incidence of the laser beam on the measured surface.

\section{Acknowledgement}

The Authors would like to thank Prof. Dr. Eng. Edward Nowak for devoted time, scientific support and successive motivation.

\section{References}

Bahadir, E., Cumhur, S., Ibrahim, B., \& Taner, U., (2010). A case study on the historical peninsula of Istanbul based on three-dimensional modeling by using photogrammetry and terrestrial laser scanning. Environmental Monitoring and Assessment, Volume 165, Issue 1-4, pp. 595-601, ISNN 0167-6369.

In Su Lee, Jae One Lee, Hong Joo Park \& Kyoung Ho Bae (2010). Influence of fitting models and point density sample in the detection of deformations of structures using terrestrial laser scanning. KSCE Journal of Civil Engineering. Vol. 14, No. 6 , pp. 905-913, ISSN 1226-7988.

Kersten, T., Mechelke, K., Lindstaedt, M. \& Sternberg, H. (2009). Methods for Geometric Accuracy Invertigations of Terrestrial Laser Scanning System. PFG Photogrammetrie Fernerkundung Geoinformation, heft 4, pp. 301-314, ISSN 14328364.

Lenda, G. (2005). Zastosowanie funkcji sklejanych w zautomatyzowanym procesie geodezyjnej kontroli kształtu powierzchni obiektów budowlanych. Application of splinesin the automated process of controlling the shape of surface of building structures, The Doctor's Thesis, Rozprawa doktorska, AGH Kraków.

Lindberg, E., Holmgren, J., Olofsson, K. \& Olsson, H., (2012). Estimation of stem attributes using a combination of terrestrial and airborne laser scanning. European Journal of Forest Research, Volume 131, Issue 6, pp. 1917-1931, ISSN 13416979.

Monserrat, O. \& Crosetto, M., (2008). Deformation measurement using terrestrial laser scanning data and least squares 3D surface matching. ISPRS Journal of Photogrammetry and Remote Sensing, Volume 63, Issue 1, January 2008, pp. 142-154, ISSN 0924-2716.

Pawłowski, W. (2008). Procedury oceny dokładności instrumentów geodezyjnych według standardów ISO mających status norm polskich. Procedures of evaluation of accuracy of surveying instruments according to ISO standards, which have the status of the Polish standards, Czasopismo techniczne, z. 2-Ś/2008, pp. 231-237. ISSN 0011-4561, 1897-6336 
PN-ISO 17123, (2005). Optyka i instrumenty optyczne - Procedury terenowe do badania instrumentów geodezyjnych i terenowych, Optics and optical instruments - Field procedures of testing surveying and field instruments

Strach, M. (2007). Wykorzystanie tachymetrów bezreflektorowych do inwentaryzacji składowisk materiałów sypkich. Utilisation of rfeflectorless tacheometers for inventorying of granular materials dumping sites, Geomatics and environmental engineering, vol. 1/3, pp. 161-172. ISSN 1898-1135

Topcon, (2013). Specyfikacja instrumentów, Specifications of instruments, http://www.tpi.com.pl/tachimetry-2

Wanic, A. (2007). Instrumentoznawstwo geodezyjne i elementy technik pomiarowych. Instrument science of surveying instruments and elements of surveying techniques, UWM Olsztyn. ISSN 978-83-7299-527-8

Woźniak, M. (2009). Bezreflektorowe systemy pomiarowe w monitorowaniu przemieszczeń. Instrukcje, wytyczne, poradniki. System kompleksowego zarządzania jakością w budownictwie. Bezdotykowe metody obserwacji i pomiarów obiektów budowlanych, Reflectorless systems of surveys in monitoring of displacements. Instructions, guidelines, hands-on, A system of complex quality management in building industry. COntact=free methods of observations and measurements of building structures. 443/2009, pp. 127-135. ISBN 978 83-2492000-6

Wunderlich, T., Wasmeier, P., Ohlmann-Lauber, J., Schafer, T. \& Reidl, F. (2013). Objective specifications of terrestrial laser scanners - A contribution of the geodetic laboratory at the Technische Universitat Munchen. Blue Series Books at the Chair of Geodesy, vol. 21, 03/2013. ISBN 978-3-943683-21-9

Zámečníková, M., Kopacik, A., (2004). Testing of Terrestrial Laser Systems Proceedings of INGEO 2004 and FIG Regional Central and Eastern European Conference on Engineering Surveying Bratislava.

\section{Authors:}

Ewa Świerczyńska, M.Sc., Eng. ${ }^{1}$, e.swierczynska@gik.pw.edu.pl

Maria Kołakowska, M.Sc.Eng. ${ }^{1)}$, m.kolakowska@gik.pw.edu.p

1) Warsaw University of Technology, Faculty of Geodesy and Cartography,

pl. Politechniki 1, 00-661 Warsaw, Poland 